\title{
A Study of Blended Teaching Mode and Practice Based on MOOC
}

\author{
Lu Ying \\ Shandong Yingcai University
}

Keywords: MOOC; blended teaching; mode and practice

\begin{abstract}
Colleges and universities are main personnel training institutions for cultivating professional talents for the society. The most important feature of higher education is to keep pace with the times. In current society with rapid development of information technology and network technology, the education field of China has proposed the concept of blended teaching. The specific analysis is conducted in this paper with respect to the connotation of MOOC blended teaching mode and the advantages of MOOC blended teaching to explore practice strategies for MOOC blended teaching, thus to fully embody the value of the MOOC blended teaching mode.
\end{abstract}

The blended teaching mode based on MOOC is an extremely advanced teaching mode that is in line with the inevitable needs of the development of the times. MOOC blended teaching can effectively give full play to the advantages of teaching and guidance. Network monitoring teaching is implemented through an informatization network not only can demonstrate the student's dominant position in teaching work, but also can inspire students' logical thinking ability, so that students can be correctly guided by their teachers to learn and create to achieve the goal of teaching work. How to effectively integrate MOOC blended teaching into the teaching work has become an important content of current teaching work. This paper conducts a comprehensive study on MOOC blended teaching mode and practice.

\section{Connotation of MOOC Blended Teaching Mode}

The so-called blended teaching is to integrate the advantages of the informatization network while retaining the advantages of traditional teachers in classroom teaching, organically combining advantages of the traditional teaching mode with the new teaching mode to achieve a multiplier effect. The blended teaching mode based on MOOC is a teaching mode extremely consistent with the current social development trend. This not only retains the advantages of traditional teaching work, but also reflects the advancement of college education work ${ }^{\mathbf{1} \mathbf{1}}$. It can be said that the blended teaching mode based on MOOC is an important milestone in higher education work, which effectively breaks the traditional education mode of single "teacher teaching - standardized test evaluation". In blended teaching mode based on MOOC, students are more advocated to carry out autonomous learning. Through the intersection of topics, students are effectively transformed into protagonists in teaching work. At the same time, blended teaching mode based on the MOOC fully follows the advantages of the network, and it can break the limitations of practice and space to realize the interaction between the classroom and extracurricular, different periods of time and places, and bring about a new realm for higher education. The teachers should effectively integrate MOOC's characteristics of the adaptability, interactivity, and collaboration with blended teaching content to enable the students to more quickly integrate into the society and adapt to the society, thus to provide a continuous stream of specialized, practical talents for the society.

\section{Advantages of MOOC Blended Teaching}

The traditional teaching mode has certain drawbacks, which singly considers the teachers as the protagonist in the teaching work, and that students can only learn by following the teacher's thinking. This to a certain extent has a negative impact on the students' ability to exert their subjective initiatives. The most important feature of MOOC teaching mode is to guide students to 
autonomously conduct cooperation, communication and problem research through some interesting and vivid teaching modes. In addition, it can achieve "student-centered" teaching work by means of the flipped classroom ${ }^{\text {'2l }}$. This can effectively motivate students' learning motivation and allow them to talk with teachers about the questions through reasonable time and place according to their own time. This not only activates the learning atmosphere, but also enables students to effectively consult the teachers about the ambiguous knowledge of themselves in a variety of teaching platforms, which has effectively narrowed the emotions between teachers and students, and enabled teachers to more profoundly understand the students' dominant position in teaching.

The teaching work conducted based on MOOC-blended teaching mode not only can make full use of the teaching resources on the Internet, but also can draw on the advantages of the online classroom teaching. With the continuous development of the current network teaching, the network teaching platform has also been improved gradually, and people can collect more specific and systematic teaching resources accordingly. The educational academia unanimously believes that blended teaching mode based on MOOC can effectively and reasonably develop the network resources and practical educational resources, which is even an important way to promote the online education work in China. At the same time, blended teaching work supported by MOOC can transfer the information of the students' work and teachers' teaching content through digital means. Both teachers and students can realize online learning interaction, which saves time and labor to a certain extent. This effectively integrates online teaching and offline teaching organically, and helps students answer questions about specific questions in details, thereby achieving the optimal allocation of the educational resources.

The famous educationist Betty Jones once said that "in the process of carrying out the education, it's no longer the main purpose of teaching by letting students have a single grasp of teaching knowledge theories, more importantly, they should make students experience the significance of classroom teaching, and experience the meaning of life, and go beyond themselves to achieve sustainable development." This is in line with China's current educational goals. With continuous development of society in China today, many enterprises in the society have also used "video conferencing" and "web conferences" to carry out their work. The content of MOOC blended teaching is the same as that of "video conferencing". The application of MOOC blended teaching mode can effectively enable the students to adapt to the future work environment in advance ${ }^{\mathbf{r} 3 \mathbf{l}}$. In addition, MOOC teaching mode also provides students with a platform for autonomous learning and self-master of knowledge, which can effectively develop students' habits of autonomous learning, and lay a solid foundation for students' future development, thereby greatly promoting students' sustainable development.

\section{MOOC Blended Teaching Practice - Taking Production and Operations Management as an Example}

The teaching management course of Production and Operations Management is a teaching subject combined with theories and practice, the teaching content involved is relatively complex. When determining teaching objectives, teachers should rigorously follow the basic requirements of the syllabus and effectively integrate the teaching work with the actual needs of the society to design the teaching objectives. According to the teaching curriculum of introducing the module in early stage of production and operation management, the teaching objective to be achieved is "to enable students to clarify the company's strategy, and conduct a detailed analysis on competition outside the company by starting from the actual situation of the company, and use scientific coordination to reasonably design for the development of the company's products and services."

In the process of classroom teaching, teachers should mainly communicate to students about the teaching content and teaching tasks. Teachers should effectively take students as teaching focus to efficiently mobilize students' subjective initiative. The teachers should actively integrate various teaching cases in classroom teaching, such as video, paper, and others, and guide students to analyze cases and allow them to consolidate the teaching knowledge in practice. Teachers should 
actively conduct the situational teaching, for example, when students learn "strategic decision-making in production operations", teachers can actively lead the students to create a teaching context for "establishing a company" '4】. In addition, the division of labor should be carried out according to various departments of the company, and the tasks of various departments should be arranged accordingly. The personnel department and financial department should conduct detailed verification and analysis of the company's own human, materials, and financial resources. The market department should conduct a detailed analysis of the market conditions outside the company and the overall market conditions. Under the condition of the division of labor and cooperation of various departments of the established company, the teachers should develop the corporate strategies suitable for the production and operation of the company. By effectively using a variety of advanced teaching means, the teachers should guide the students to experience the requirements of all aspects of the correct production and operation strategy decision-making while stimulating the students' interest in learning. In this way, the teachers can make the students to be familiar with the teaching knowledge content in a pleasant teaching process.

\section{Design of Network Teaching}

When carrying out the network teaching, teachers can use the interactive practice methods such as the video learning and others to guide the students to have real-time communication by combining the actual situation of teaching work. The teachers can use the unified time every week to conduct the real-time teaching of key and difficult knowledge found in the teaching process by combining with students' feedback. Simultaneously, the teachers can lead the students to review the knowledge content of the unit, so that students can consolidate teaching knowledge ${ }^{\mathbf{r} 5 \mathbf{l}}$. While conducting the network teaching explanations, teachers can vividly and intuitively display the obscure knowledge difficult to be understood on the exchange platform, such as the relevant factors of "requirements for forecasting", which is conducted in the form of courseware. In addition, such knowledge should be timely uploaded to the "Shared Documents of exchange platform", so that the teachers can enable the students to effectively master the relevant content affecting the decision-making the production demands while conducting explanations. The teachers should effectively consolidate key and difficult points of teaching work of Production and Operations Management through the Q\&A and the form of checking the lost knowledge and making up for them, thus to improve students' professional knowledge.

\section{Design of Network Collaborative Learning}

Network collaborative learning refers that students in small groups conduct a common discussion within a fixed period of time through the means of the Internet interactive platform in accordance with the actual teaching tasks given by the teachers, and answer the questions given by teachers and give feedbacks to the teachers through the form of PPT and its data content. For example, when producing the "SWOT Analysis Chart for Production Operations Strategic Decisions", teachers can give students a "background of logistics transportation company" to allow the students to conduct a comprehensive analysis according to internal strengths, internal weaknesses, external opportunities, and external threats of the company by using the Internet. In addition, the students formulate a "SWOT analysis chart" through PPT, and summarize the relevant recommendations of "the strategic decision of the transportation enterprise's production and operation" combined with the form of the chart. The teachers should conduct a good division of labor of the students effectively through the network collaborative learning mode. The teachers should give the students a good platform for exchanges and communication at anytime, anywhere through the form of video interaction. This is to effectively enable students to learn how to use the Internet to retrieve the information needed, and enable students to enhance their own awareness of cooperation in network interaction and communication, thus to develop students' production and operation management thinking, and enable students to consolidate knowledge in collaborative practice. 


\section{Design of Fragmented Autonomous Learning}

The so-called fragmented autonomous learning means that teachers can give students a fixed concept and related courseware for teaching work process before starting the examination, and allow the students to preview the knowledge through a platform for information exchange. Students can arrange their own time and conduct the detailed review work according to the teaching content. Meanwhile, in the knowledge review stage, the teachers can also actively use the fragmented teaching mode to conduct the knowledge preview. During the process of conducting the preview work, teachers can display the key knowledge points of the class and the chapter by using the interactive platform through forms of "mind map" and "knowledge moments", so that students can conduct the autonomous learning work according against fragmented knowledge content in the convenient time period, which effectively break the barriers of time and space, and they can realize the goal of autonomous learning at any time anywhere. ${ }^{\mathbf{I} 6 \mathbf{1}}$ For example, when previewing "Product Development and Service Design," teachers can release important knowledge of product development goals, product development principles, product development factors, and responsibilities of various departments and others on the class "WeChat public teaching platform" in real time in the form of courseware. In this way, even when students are on a bus, they can also preview the knowledge to be learned at anytime and anywhere. The active use of the fragmented autonomous learning mode effectively embodies the student's dominant position in teaching and exercises their autonomous learning ability.

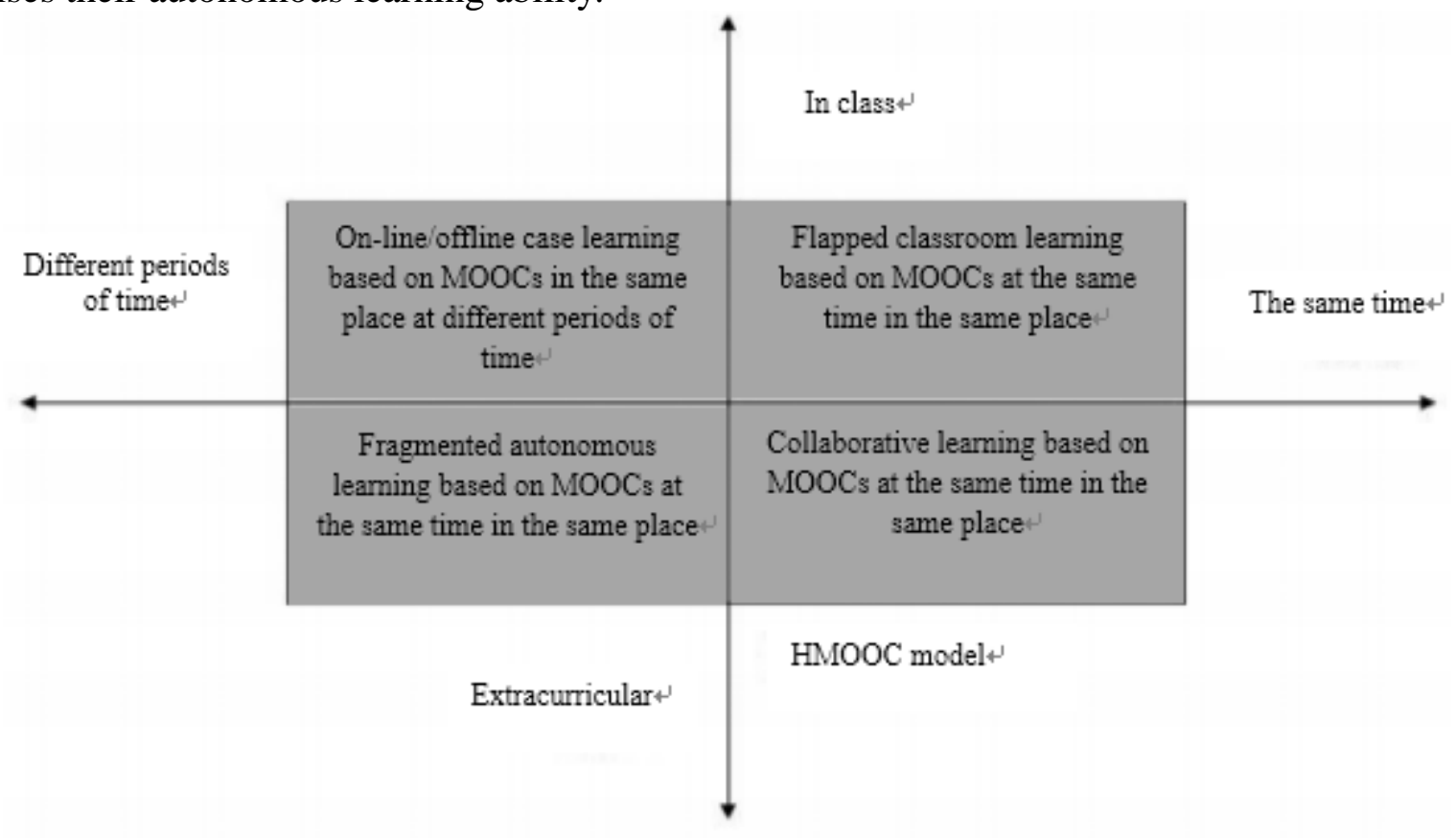

Fig.1 Diagram of MOOC blended teaching mode

\section{Conclusion}

In a word, the blended teaching mode based on MOOC is a teaching mode with high efficiency. The MOOC blended teaching mode not only can capture dual advantages of the traditional teaching mode and the informatization teaching mode, but also can realize optimal teaching resources, and promote scientific development of the students, thus to create a good teaching atmosphere. MOOC blended teaching mode has a wide range of applications and is applicable to all majors in college education. Through flipped class teaching, Internet interactive teaching, fragmented autonomous learning, and assisted online learning, so as to make every aspect of teaching run through all aspects of MOOC blended teaching work. This effectively cultivate the students to have good autonomous learning habit while highlighting advancement of teaching work in the colleges and universities, thus to lay a good foundation for the future development of students. 


\section{Acknowledgment}

Research project: Shandong Provincial Vocational Education Teaching Reform Research (Key) Project [2017299]

Shandong Yingcai University Teaching Reform Project [YCXY-X2015046]

\section{References}

[1] Zhang Guofu, Zang Yuping, Shen Hongyan and so on. In the context of transformation, the mixed teaching mode based on MOOC was studied in [J]., 2017 (2).

[2] Qiang Jun, Zhou Ming, Wang Jun. Reform and practice of hybrid teaching mode based on MOOC [J]. Journal of XiangNan University, 2017, 38 (2): 94-97.

[3] Xiong Jiahui and Wu Jiaoli. Based on MOOC's hybrid teaching mode, we designed [J]. curriculum education research, 2015 (27): 32-33.

[4] Luo Guiqiong. Application of blended teaching mode based on MOOC -- take computer course as an example, [J]. Asia Pacific Education, 2016 (33): 118-118.

[5] Liu Yanchun, Liu Cuicui. The application of blended teaching mode based on MOOC in art courses: [J]. art education, 2017 (3): 285-286.

[6] Chen Ping. MOOC based college applied writing hybrid teaching mode research [J]. science consulting (technology and management), 2016 (5): 179-180.

About the author: Lu Ying (04/1976-), female, Han (nationality), born in Gaotang, Shandong, graduating with a master's degree, and currently working in Shandong Yingcai University.

Associate Professor, interested in Regional Economic Development, Investment and Financing Management. 